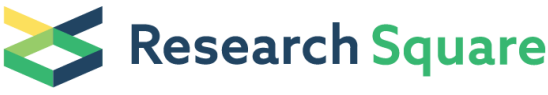

\section{Mutational screening of the TPO and DUOX2 genes in Argentinian children with congenital hypothyroidism due to thyroid dyshormonogenesis.}

\section{Maricel F. Molina}

Universidad de Buenos Aires Facultad de Farmacia y Bioquimica

\section{Patricia Papendieck}

El Hospital de Ninos Ricardo Gutierrez Division de Endocrinologia

\section{Gabriela Sobrero}

El Hospital de Niños "Santísima Trinidad" Servicio de Endocrinología

\section{Viviana A. Balbi}

Hospital de Niños "Sor María Ludovica" Servicio de Endocrinología

\section{Fiorella S. Belforte}

Universidad de Buenos Aires Facultad de Farmacia y Bioquimica

\section{Elena Bueno Martínez}

University of Salamanca Faculty of Medicine: Universidad de Salamanca Facultad de Medicina

\section{Ezequiela Adrover}

Universidad de Buenos Aires Facultad de Farmacia y Bioquimica

\section{María C. Olcese}

Universidad de Buenos Aires Facultad de Farmacia y Bioquimica

\section{Ana Elena Chiesa}

El Hospital de Ninos Ricardo Gutierrez Division de Endocrinologia

\section{Mirta Beatriz Miras}

Hospital de Niños "Santisima Trinidad" Servicio de Endocrinología

Verónica G. González

Hospital de niños "Sor María Ludovica Servicio de Endocrinología

\section{Mauricio Gomes Pio}

Universidad de Buenos Aires Facultad de Farmacia y Bioquimica

\section{Rogelio González-Sarmiento}

University of Salamanca Faculty of Medicine: Universidad de Salamanca Facultad de Medicina Héctor Manuel Targovnik

Universidad de Buenos Aires Facultad de Farmacia y Bioquimica

Carina Marcela Rivolta ( $\nabla$ cmrivolta@yahoo.com.ar)

Universidad de Buenos Aires Facultad de Farmacia y Bioquimica https://orcid.org/0000-0001-9484$368 X$ 


\section{Research Article}

Keywords: Thyroid Peroxidase, DUOX2, Gene, Mutation, Congenital Hypothyroidism, Thyroid Dyshormonogenesis

Posted Date: January 13th, 2022

DOI: https://doi.org/10.21203/rs.3.rs-1239485/v1

License: (9) (i) This work is licensed under a Creative Commons Attribution 4.0 International License. Read Full License 


\section{Abstract \\ Purpose}

Primary congenital hypothyroidism $(\mathrm{CH})$ is the most common endocrine disease in children and one of the preventable causes of both cognitive and motor deficits. We present a genetic and bioinformatics investigation of rational clinical design in 16 Argentine patients suspected of $\mathrm{CH}$ due to thyroid dyshormonogenesis (TDH).

\section{Methods}

Next-Generation Sequencing approach was used to identify variants in Thyroid Peroxidase (TPO) and Dual Oxidase 2 (DUOX2) genes. A custom panel targeting 7 genes associated with TDH [(TPO, lodothyrosine Deiodinase I (IYD), Solute Carrier Family 26 Member 4 (SLC26A4), Thyroglobulin (TG), (DUOX2), Dual Oxidase Maturation Factor 2 (DUOXA2), Solute Carrier Family 5 Member 5 (SLC5A5)] and 4 associated with thyroid dysembryogenesis [PAX8, FOXE1, NKX2-1, Thyroid Stimulating Hormone Receptor (TSHR)] has been designed. Additionally, bioinformatic analysis and structural modeling were carried out to predict the disease-causing potential variants.

\section{Results}

Five novel variants have been identified, two in TPO: c.2749-2A>C and c.2752_2753delAG, [p.Ser918Cysfs ${ }^{*} 62$ ] and three variants in DUOX2 gene: c.425C>G [p.Pro142Arg]; c.790delC [p.Leu264Cysfs*57] and c.2695delC [p.GIn899Serfs*21]. Seventeen identified TPO, DUOX2 and IYD variants were previously described. We identified potentially pahogenic bi-allelic variants in TPO and DUOX2 in 8 and 2 patients, respectively. We also detected a potentially pathogenic mono-allelic variant in TPO and DUOX2 in 4 and 1 patients respectively. Only two patients were heterozygous for digenic variants in TPO/IYD and in TPO/DUOX2 genes.

\section{Conclusions}

22 variants have been identified associated with TDH. All described novel mutations occur in domains important for protein structure and function, predicting the TDH phenotype.

\section{Introduction}

Congenital hypothyroidism $(\mathrm{CH})$ is the most common inherited neonatal endocrine disorder, affects an estimated 1 in 2,000-4,000 newborns and it is characterized by elevated levels of thyroid stimulating hormone (TSH) and low thyroid hormones $(\mathrm{TH})$ serum levels [1-3]. If untreated, $\mathrm{CH}$ can lead to permanent intellectual disability and slow growth. 
According to the candidate genes associated with primary $\mathrm{CH}$, this pathology can be divided into two groups: (a) disorders of thyroid gland development (thyroid dysembriogenesis or thyroid dysgenesis group) or (b) defects in any of the steps of thyroid hormone synthesis (thyroid dyshormonogenesis (TDH) group) [1-3]. The thyroid dysembryogenesis, accounts for the $80-85 \%$ of the cases in Caucasians. TDH, which accounts for the remaining $15-20 \%$ of the cases, has been associated to variants in the Solute Carrier Family 5 Member 5 (SLC5A5) (encoding NIS), Solute Carrier Family 26 Member 4 (SLC26A4) (encoding pendrin), Solute Carrier Family 26 Member 7 (SLC26A7), Thyroid Peroxidase (TPO), Dual Oxidase 1 (DUOX1), DUOX Maturation Factor 1 (DUOXA1), Dual Oxidase 2 (DUOX2), DUOX Maturation Factor 2 (DUOXA2), lodotyrosine Deiodinase (IYD) and Thyroglobulin (TG) genes [1-3]. These mutations produce a heterogeneous spectrum of $\mathrm{CH}$ with Gland-in-situ (GIS) of normal or enlarged size, characterized usually by an autosomal recessive inheritance. Thereafter, the patients are typically homozygous or compound heterozygous for the mutations and their parents, carriers of one variant. lodide Organification Defects (IOD) are linked with inactivating mutations in the TPO, DUOX1, DUOX2, DUOXA1, DUOXA2, SLC26A4 or SLC26A7 genes [4]. Variants in TPO and DUOX2 appear to be the most common cause of IOD. Recently, Wang et al., [5] analyzed a large cohort of patients with $\mathrm{CH}$ in the Chinese population, identifying a high incidence of DUOX2 variants in patients with GIS, suggesting that DUOX2 variants may confer susceptibility to GIS via polygenic inheritance.

The aim of our study was to identify and conduct a thorough assessment of the TPO and DUOX2 variants in sixteen patients from unrelated families with $\mathrm{CH}$ due to $\mathrm{TDH}$. Five novel variants have been identified, two in TPO gene and three variants in DUOX2 gene.

\section{Materials And Methods}

\section{Patients}

Patients with $\mathrm{CH}$, goiter, high TG levels and negative anti-TG and anti-TPO auto antibodies were selected to participate in this study (Supplementary Figure 1). Patients from families 1, 3, 4, 5, 7, 10, 11, 12 and 15 were followed at Endocrine Division of Hospital de Niños "Ricardo Gutiérrez", patients from families 2, 6, 8, 9 and 14 were followed at Endocrine Unit of Hospital de Niños "Santísima Trinidad" and patients from families 13 and 16 were followed at Servicio de Endocrinología of Hospital de Niños "Sor María Ludovica". The case reports of each of the patients analyzed are shown in Supplementary Notes 1. Table 1 shows the clinical and biochemical characteristics of the patients studied. Replacement treatment was started with a daily dose of L-thyroxine (L-T4) of $12-15 \mu \mathrm{g} / \mathrm{kg}$ of weight for each child.

\section{Next-Generation Sequencing}

A custom panel targeting 7 genes associated with TDH (SLC5A5, SLC26A4, DUOX2, DUOXA2, TPO, IYD, TG) and 4 associated with thyroid dysembryogenesis (PAX8, FOXE1, NKX2-1, TSH receptor (TSHR) has been designed in order to amplify all exons and exon-intron junctions of the 
respective genes by multiplex PCR. Genomic DNA was isolated from peripheral blood leucocytes by the standard cetyl trimethyl ammonium bromide method. The TruSeq NGS libraries were prepared according to the manufacturer's instructions (Truseq Custom Amplicon Library Preparation, Illumina, San Diego, CA). Pooled libraries were sequenced on an Illumina MiSeq sequencer (Illumina). Basic data analysis was performed according to the default parameters of the Illumina Variant Studio versión 22.1 software. For each subject, a .vcf file containing variant was generated, further reviewed, and filtered. For every equivocal call in the .vcf files, visual inspection of the mapped data was performed using the Integrated Genomics Viewer 2.4 software (IGV; Broad Institute, Cambridge, MA, USA). All variants detected in the patients were further validated by Sanger sequencing using the primers and PCR conditions reported previously [6,7].

\section{Protein homology analysis}

Amino acid sequence homology between several TPO species and between several DUOX2 species was investigated using the MegAlign (DNASTAR, Hauser University of California-SF) and Search for Conserved Domains (http://www.ncbi.nlm.nih.gov/BLAST) software programs.

\section{Amino acid substitution prediction tools.}

Missense variants were analyzed with the sequence based predictors: Protein Variation Effect Analyzer (PROVEAN) and Sorting Intolerant From Tolerant (SIFT) [http://provean.jcvi.org/genome_submit_2.php? species=human], Polymorphism Phenotyping v2 (PolyPhen-2, HumVar trained model) [http://genetics.bwh.harvard.edu/pph2/], PANTHER-Position-Specific Evolutionary Preservation (PSEP) [http://www.pantherdb.org/tools/csnpScoreForm.jsp?] and MutPred2 [http://mutpred.mutdb.org/].

\section{Splice site prediction tools}

Searching for potential $5^{\prime}$ and $3^{\prime}$ splice site (ss) sequences in the TPO gene was accomplished using the NNSplice [http://www.fruitfly.org/seq_tools/splice.html], FSplice [http://linux1.softberry.com/berry.phtml? topic=fsplice\&group=programs\&subgroup=gfind], SPL [http://linux1.softberry.com/berry.phtml? topic=spl\&group=programs\&subgroup=gfind] and SPLM [http://linux 1. softberry.com/berry.phtml? topic=splm\&group=programs\&subgroup=gfind] prediction tools. Scores of the 23 -nt sequences (20 bases in the intron and 3 bases in the exon), corresponding either to wild-type and mutated 3 ' ss, were calculated by means of the MaxEntScan program [http://genes.mit.edu/burgelab/maxent/Xmaxentscan_scoreseq_acc.html]. Finally, the analysis of exon sequences that allows the identification of putative exonic splicing enhancer (ESE) responsive to 
the human Ser/Arg-rich proteins (SR proteins) was performed using the ESEfinder program [http://rulai.cshl.edu/tools/ESE/].

\section{Classification and determination of pathogenicity}

We applied American College of Medical Genetics and Genomics (ACMG) recommendations to classify variants as pathogenic, likely pathogenic, variants of uncertain significance (VUS), likely benign, or benign [8]. Variants classified as either pathogenic or likely pathogenic were considered to be involved in the $\mathrm{CH}$ development.

\section{D modeling analysis of the identified TPO, DUOX2 and IYD variants}

In order to study the three-dimensional (3D) structure, homology models were generated by using the Swiss Model program [https://swissmodel.expasy.org]. The best scored template among many generated by Swiss Model was chosen in each case in order to create a suitable TPO and DUOX2 structure models. Available crystal structures of IYD are shorter versions of the protein which do not include the position 292. So, a structure model of the full protein, in particular isoform 2 , was created using the RaptorX Structure Prediction program [http://raptorx.uchicago.edu]. In order to validate the created TPO, DUOX2 and IYD models, we used Verify3D program and ERRAT program from SAVES v6.0 server [http://saves.mbi.ucla.edu] and QMEAN from Swiss Model [http://swissmodel.expasy.org/qmean/]. The different protein models were submitted to the Swiss PDB Viewer v4.1.0 [https://spdbv.vital-it.ch/] in order to evaluate potential structure changes due to mutations. Stability changes were calculated using the FoldX [http://foldxsuite.crg.eu/] suite through the artificial reality application YASARA [http://www.yasara.org/].

\section{Results}

\section{Screening of variants in the TPO and DUOX2 genes}

In order to identify the deleterious TPO and DUOX2 variants from the index patients of 16 unrelated families, all exons of the TPO and DUOX2 genes with their exon/intron boundaries were screened by NGS (Figure 1a,b).

A total of 21 variants have been identified, 15 in TPO and 6 in DUOX2 gene (Figure 1 a,b; Table 2). In regards to $T P O$, two novel variants associated with thyroid disease were identified. One of them, detected in Family 6: II-1, consists of an adenine to cytosine transversion in the acceptor splice site of intron 16 (c.2749-2A>C) (Figure 1a; Table 2). The other one is a deletion of adenine and guanine at nucleotide positions c.2752 and 2753 (c.2752_2753delAG, p.Ser918Cysfs*62) in the index Family 13: II-1. Two identified variants, c.1727C>A (p.Ala576Glu) in Family 4: II-1 and Family 5:II-3 (Figure 1a; Table 2), and 
c.2116A>G (p.Met706Val) in Family 9: II-3 (Figure 1b; Table 2) have not been associated previously to $\mathrm{CH}$ and have been recorded in gnomAD and in dbSNP databases (Table 2). Only one allele of a total alleles number of 251454 has been identified in population latino/admixed American presenting an estimated total Minor Allele Frequency (MAF) of $0.000003977 \%$ for the allele adenine ${ }^{1727}$. Guanine ${ }^{2116}$ is present with a frequency of 0,0158 in gnomAD. This variant was widely distributed in all populations in heterozygous state. Additionaly it appears as homozygous in African/African-American population.

If we refer to DUOX2 gene, three novel variants associated with thyroid disease have been identified. The first variant, characterized in Family 15: II-1 was the c.425C>G (p.Pro142Arg) (Figure 1b; Table 2). The second variant, also identified in Family 15:II-1 was the c.790delC (p.Leu264Cysfs*57) (Figure 1b; Table 2). The third novel variant found in the Family 14: Il-1 consists of another cytosine deletion, c.2695delC (p.GIn899Serfs*21) (Figure 1b; Table 2). Although the variant present in the Family 16: II-1, c.2759C>T (p.Thr920lle) (Figure 1b; Table 2), has not been associated with $\mathrm{CH}$, has been registered in dbSNP (rs1401530068) and in gnomAD presenting a MAF of $0.000003976 \%$ for the allele adenine ${ }^{920}(1 / 251478$ alleles).

In addition to the variants identified in the TPO and DUOX2 genes, only one variant was detected in the rest of the genes screened by the NGS panel. A missense variant (c.874C>T, p.Arg292Cys) was identified in IYD gene (Family 6: II-1), which have not been associated previously to $\mathrm{CH}$ and have been recorded in gnomAD and in dbSNP databases (Figure 1a; Table 2).

The genotypes associated to the clinical and biochemical characteristics of the patients studied are shown in Table 1; the segregation analysis is shown in Figure 1a and $1 \mathrm{~b}$.

\section{Protein homology analysis}

Multiple sequence alignment of the p.Ala576Glu and p.Met706Val human TPO variants with other animal wild-type TPO sequences found in the GenBank database, using Clustal method, revealed that wild-type alanine ${ }^{576}$ residue is strictely conserved in all TPO species analyzed (Supplementary Figure 2). In contrast, wild-type methionine ${ }^{706}$ is not conserved. However, valine ${ }^{706}$ is present in the species Rattus norvergicus and Mus musculus (Supplementary Figure 2). Aditionally, evolutionary conservation degree studies were conducted for p.Pro142Arg and p.Thr920lle. Our results show that both proline ${ }^{142}$ and threonine ${ }^{920}$ are highly conserved in evolution (Supplementary Figure 3).

\section{Classification and determination of pathogenicity.}

\section{Amino acid prediction analysis in missense variants.}


In order to analyze and classify the missense variants identified, a bioinformatic prediction study was performed. The in silico algorithms PROVEAN, SIFT, Polyphen 2-Hum Var, PANTHER-PSEP and MutPred2 were used to predict the levels of pathogenicity of each variant. The sequence variants were then classified according to the results of these programs and ACMG standards and guidelines, grouping them according to the coincidence shown among the programs. The classification guidelines of the missense variants and their predictions are exhibited in Table 3. The predictors exhibited as likely pathogenic the TPO variants: p.Asn307Thr, p.Pro499Leu, p.Thr561Met, p.Ala576Glu, p.GIn660Glu, p.Arg665Trp, p.Val748Met and p.Glu799Lys, whereas the p.Ser398Thr was classified as VUS and p.Met706Val as likely benign variant. When analyzing the DUOX2 variants, we can see that of the 3 of the variants that were identified, two belong to VUS group (p.Pro138Leu and p.Pro142Arg) and the remaining to the likely pathogenic variants group ( $p$.Thr920lle). The p.Arg292Cys variant in the IYD was classified as likely benign.

\section{3'Splice site prediction analysis}

In order to evaluate in silico the relevance of the c.2007-9_-7delTCT and c.2749-2A>C TPO variants, wildtype and mutated 3'ss located in the introns 11 and 16, respectively were analized using the NNSplice, FSplice, SPL and SPLM tools. As shown in Figure 2a, the both wild-type 3'ss were recognized by all four programs. NNSplice does not recognize the mutated 3' ss located in the intron 11, while the rest of the programs only showed a slightly lower score in relation to the wild-type 3' ss. Regarding mutated 3' ss located in the intron 16, it was not identified as an acceptor site of splicing by NNSplice, FSplice, SPL and SPLM programs (Figure 2a).

The strength of mutated and physiologic 3'ss sites were also compared by MaxEntScan program, maximum entropy model (MAXENT), the first-order Markov model (MM) and the weight matrix model (WMM) and the scores were consistently lower for the mutated 3' ss with respect to wild-type 3' ss (Figure 2a) in both variants (c.2007-9_-7delTCT and c.2749-2A>C).

ESE sequences act as binding sites for SR proteins (SF2/ASF, SC35, SRp40 and SRp55). Both mutated and wild type 3 ' ss in both variants (c.2007-9_-7delTCT and c.2749-2A>C) were recognized by SF2/ASF, SC35, SRp40 and SRp55 proteins. Interestingly, according to ESEfinder, c.2007-9_-7delTCT variant decreases the score of the SRp40 proteins that bind to ESE sequences located around the intron 11/exon 12 junction (Figure $2 b$ ), whereas c.2749-2A>C variant decreases the score of the SRp40 and SF2/ASF proteins that bind to ESE sequences located around the intron 16/exon 17 junction (Figure $2 b)$.

\section{D modeling analysis of the identified TPO, DUOX2 and IYD mutants}


In order to study the consequences in the protein structure and function and to achieve a possible explanation of the pathogenic mechanism of the identified variants, we carried out in silico studies. The quality of the created TPO, DUOX2 and IYD structure models was evaluated using Verify3D, ERRAT and QMEAN programs. According to Verify3D our models passed the test with $92.86 \%$ ( $\left.\mathrm{TPO}_{\text {peroxidase domain }}\right)$, $100 \%\left(\mathrm{TPO}_{\mathrm{CCP}}\right.$ domain $), 100 \%$ (TPO EGF-like domain $)$ and $81.91 \%$ (IYD); amino acids scored $\geq 0.2$ in the 3D/1D profile. The overall quality factors were $85.91\left(\mathrm{TPO}_{\text {peroxidase domain }}\right), 84.61\left(\mathrm{TPO}_{\mathrm{CCP} \text { domain }}\right), 53.12\left(\mathrm{TPO}_{\mathrm{EGF}}\right.$ like domain), 94.63 (DUOX2) and 93.88 (IYD). In accordance with QMEAN4, the chosen models were suitable with scores of -1.72 for $\mathrm{TPO}_{\text {peroxidase domain, }}-0.63$ for $\mathrm{TPO}_{\mathrm{CCP} \text { domain, }}-1.97$ for $\mathrm{TPO}_{\mathrm{EGF}-\text { like domain, }}-2.17$ for DUOX2 and -0.78 for IYD. To evaluate the impact of the identified variants on 3D structure of proteins we submitted the created models to Swiss PDB Viewer and the FoldX suite. Then, comparative analysis between wild type and mutated proteins (carrying the identified missense mutations) was carried out by studying conformational and molecular changes (see Supplementary Notes 2) (Figure 3). Also, the electrostatic potential surface which is explained as the distribution of exposed charges in the protein surface, was calculated for each variant. In addition, using FoldX suite we obtained the stability changes for each variant. This parameter can be calculated as the difference between the free energy of the wildtype (WT) and the mutant (MT) protein: $\Delta \Delta \mathrm{G}$ (change) $=\Delta \mathrm{G}(\mathrm{MT})-\Delta \mathrm{G}(\mathrm{WT})$. If this value is above 0 the variant is destabilizing (with an error margin of $0.5 \mathrm{kcal} / \mathrm{mol}$ ).

\section{Discussion}

The present study reveals the clinical and molecular analysis of a cohort of sixteen children from unrelated families with $\mathrm{CH}$ and IOD in Argentinian population. Patients with IOD have a variable degree of primary hypothyroidism characterized by elevated TG serum levels, an increased and rapid uptake of iodine, a significant discharge of thyroidal radioiodine after perchlorate discharge test (PDT) (Supplementary Figure 1) and a thyroid gland enlargement depending on the severity of the defect. PDT allows to distinguish Total IOD (TIOD) from Partial IOD (PIOD, between 10 and 90\%) [1]. In untreated patients, a complete defect causes a severe phenotype resulting in mental retardation with a large goiter. Due to late initiation of treatment, many late-diagnosed hypothyroid patients suffer typical signs and symptoms of hypothyroidism even though they receive regular L- $\mathrm{T}_{4}$ treatment. Unfortunely this is the case of some of our patients who, together with others who interrupted their treatment for different reasons, experimented severe repercussions (patients 3:II-1, 4:II-1, 5:II-3, 6:II-1, 7:II-1, 8:II-1, 8:II-2, 12:II-1) (Supplementary Notes 1). So, they needed psycho-pedagogical or phonoaudiological assistance. The remaining 8 patients (1:II-1, 2:II-1, 9:II-3, 10:II-1, 11:II-1, 13:II-1, 14:II-1, 15:II-1 and 16:II-1) grew and developed normally attending normal schooling with good performance (Supplementary Notes 1). All the cases studied correspond to permanent $\mathrm{CH}(\mathrm{PCH})$ except the index patients of the families 10 and 11 whom transient $\mathrm{CH}(\mathrm{TCH})$ was diagnosed. It has been reported that TDH can cause $\mathrm{PCH}$ or TCH [52]. Although variants in TPO and DUOX2 appear to be the most common cause of IOD, patients with hipoplasia and non-goitrous hypothyroidism have been reported recently harboring TPO [53] and DUOX2 mutations [50]. 
Previous reports indicate that $\mathrm{CH}$ caused by variants in the TPO gene is an autosomal recessive disorder, and most patients with biallelic TPO variants have PCH [13]. In the present study, TPO variants have been associated to $\mathrm{TCH}$ as can been seen in the index patients of family 10 and 11 who presented severe hypothyroidism in the neonatal period.

Most cases of $\mathrm{CH}$ associated with alterations in the DUOX2 gene are caused by either biallelic or monoallelic variants which lead to extremely complex correlation between DUOX2 genotypes and clinical phenotypes [49,54,55]. Both biallelic and monoallelic DUOX2 variants could be associated with TCH or $\mathrm{PCH}[13,46,55-57]$. DUOXA2 variants also are associated with TCH or PCH $[1,55]$. Recently, Lui et al. [58] identified two monoallelic missense variants in DUOX1 and DUOXA1 genes causing TCH and PCH, respectively. Of note, biallelic inactivation of $T G, S L C 5 A, S L C 26 A 4$ or $S L C 26 A 7$ causes PCH too $[59,60]$.

Molecular diagnosis of $\mathrm{CH}$ has been traditionally established by PCR-based approaches followed by systematic Sanger sequencing analysis. The identification of simultaneous variants in the same gene or in different thyroid specific genes by introduction of NGS platforms contributes to the accurate diagnosis and classification of the defects $\mathrm{CH}$. TPO and DUOXs variants were identified in a total of 205 (in 38 papers) and 663 (in 40 papers) patients with CH, respectively, using targeted NGS panel (TNGS) or wholeexome sequencing (WES). Patients and variants are summarized in Supplementaries Tables 1 and 2. These findings suggested that, not only monogenic inheritance, but also digenic or oligogenic inheritance are involved in the pathogenesis of IOD.

In this report, we have identified novel variants associated with $\mathrm{CH}$ and other variants previously described. Some of the latter were not associated with this pathology. So, ours results show that variants were most frequently found in TPO (68.2\%), followed by DUOX2 (27.3\%) and IYD (4.5\%) genes. No definitively variants were found in SLC5A5, SLC26A4, DUOXA2 and TG by NGS technology. 10 missense mutations, 2 splice site variants, 2 duplications and 1 deletion were identified in TPO gene (Figure 4a), whereas, 6 variants were identified in DUOX2 gene: 3 missense and 3 deletions (Figure 4b). Only 1 missense variant was identified in IYD gene. Sixteen out of a total number of 22 variants was identified as likely pathogenic variants. We have identified 3 likely benign variants, two of them, in TPO gene: p.Met706Val and c.2007-9_-7delTCT and the other, in IYD gene: p.Arg292Cys as it was evidenced by Clinvar database and our studies using in silico predictive tools, whereas 3 variants, 1 in TPO (p.Ser398Thr) and two in DUOX2 gene (p.Pro138Leu and p.Pro142Arg) were classified as VUS. 13 variants are found in the extracellular portion of the TPO (Figure 4), in the myeloperoxidase (MPO)-like domain: p.Asn307Thr, p.Ala397Profs*76, p.Ser398Thr, p.Pro499Leu, p.Thr561 Met, p.Ala576Glu, p.GIn660Glu, p.Arg665Trp, c.2007-9_-7delTCT and p.Met706Val; in the Sushi domain: p.Val748Met and in the EGF domain: p.Glu799Lys and p.Cys808Leufs*72. Two variants are located in the intracellular part of TPO: c.2749-2A>C and p.Ser918Cysfs*62 (Figure 4).

The most frequent variants are, the reported previously p.Val748Met identified in 4 patients, the p.Thr561Met presents in 3 patients, the p.Ala397Profs ${ }^{\star} 76$ found in 2 patients and the p.Asn307Thr identified en 2 patients too. The pathogenic p.Val748Met variant produces several changes in molecular surface. Significant structural alterations have been detected in the p.Thr561Met variant, which would 
alter the secundary structure and affect the function of TPO protein. Our results agree with the investigations of Fu et al. [13]. On the other hand additional prediction studies would indicate the pathogenity of the p.Thr561Met variant. The p.Ala397Profs*76, described for the first time by Abramowicz et al. [31] is a common alteration of the TPO gene in Caucasian population.

The p.Asn307Thr identified previously in our laboratory [7] has been classified in the present study as likely pathogenic variant. The change origines a new hydrogen bond, a local increase in electropositive charges. On the other hand, the position 307 is a known glycoslylation site for which we hyphotesize that the alteration of the normal protein glycosylation pattern could affect its transport and correct localization in the thyrocyte membrane.

Three variants identified here have been previously functionally characterized, p.Ser398Thr $[9,10]$, p.Pro499Leu [12] and p.Glu799Lys [27]. The variant p.Ser398Thr has been classified by us as VUS, which would be consistent with the following explanations: (a) the 3D modelling analysis of the p.Ser398Thr showed the breaking of a hydrogen bond between an asparagine at position 557 and an isoleucine at position 497 and several changes in the molecular surface of the mutated protein; (b) Guria et al. [9], demostrated that p.Ser398Thr had and slightly decreased enzyme activity determinated by the I- and guaiacol assays, this findings are consistent with the molecular docking-based study carried out by Begum et al. [10] in which p.Ser398Thr showed a moderate influence on the interaction between the TPO protein and the heme prosthetic group. If we establish a genotype-phenotype relationship, we could hypothesize that this variant would not be the cause of the $\mathrm{CH}$, since the mother and one of the index patient's siblings are euthyroid and homozygous for it (Figure 1a). In a previous work we have functionally analyzed the p.Pro499Leu variant, described here as likely pathogenic variant using the Baculovirus System as a model of enzyme expression of human TPO. Significantly lower activity was recorded [12]. Bikker et al. [27] expressed the p.Glu799Lys in CHO-K1 cells. The protein appeared to insert normally in the cell membrane, since it showed distribution similar to that of wild-type TPO. The position of the variant is far from the active site, but still the mutant protein is devoid of enzymatic activity, suggesting that the exchange of an acidic for a basic amino acid in exon 14 may lead to improper folding of the molecule [28].

Most cases of $\mathrm{CH}$ associated with alterations in the TPO gene are caused by either homozygous or compound heterozygous genotypes. However, two or even more variations in one or more $\mathrm{CH}$ associated genes can be found in a single patient, and the coexistence of multiple variants may affect the severity of the hypothyroid condition. In the present study, a variant heterozygous for c.2749-2A>C in TPO combined with the heterozygous IYD variant for p.Arg292Cys were identified in patient 6: II-1 and three variants have been identified in patient 9:II-3, two in TPO gene: the homozygous p.Met706Val and the heterozygous p.Val748M and one homozygous variant in DUOX2 gene: p.Pro138Leu.

Aditionally we have identified 6 DUOX2 variants. p.Pro138Leu, p.Pro142Arg and p.Leu264Cysfs 57 are located in the peroxidase-like domain, whereas p.GIn899Serfs $* 21$, p.Thr920lle and p.Phe966Serfs 29 are present in the transmembrane domain. Only two variants were described previously associated with congenital hypothyroidism, the p.Pro138Leu $[46,47]$ and the p.Phe966Serfs 29 variant $[6,11,24,40,41$, 
46, 48-51]. The frameshift p.Phe966Serfs 29 , commonly reported as p.S965fsX994 is one of the most frequent mutations in DUOX2 gene. Muzza et al. [46] showed that the transcripts carrying this deletion were submitted to nonsense mRNA decay, indicating the existence of mRNA quality control active on the DUOX2 gene. Despite p.Pro138Leu appears functionally silent, with limited damaging impact, has been significantly associated with $\mathrm{CH}$ in Japanese and Italian patients and has been classified in this study as VUS [60]. Several molecular surface changes can be seen in the affected area and in the whole protein in our 3D modeling analysis.

In this study, eight patients were monogenic and compound heterozygous for variants in TPO and DUOX2 genes (Patients 1:II-1, 2:II-1, 3:II-1, 4:II-1, 5:II-3, 7:II-1, 14:II-1, 15:II-1). All of them harbored variants that were possibly contributing to $\mathrm{CH}$. Five likely pathogenic and monoallelic variants have been identified here, all of them were absent in the healthy control (Patients 8:II-1 and 8:II-2, 11:II-1, 12:II-1, 13:II-1, 16:II-1). These variants are usually assumed to coexist with an additional undetected CNV, intronic or regulatory mutation on the other chromosome [40]. This may occur in our patients since the sequencing techniques used here would not detect mutations in noncoding regions of the genome and although CNVs were not identified. On the other hand, monoallelic variants could coexist with other genes not incorporated in the design of our panel and that also contribute to the hypothyroid phenotype. Only two patients were heterozygous for digenic variants in TPO/IYD (6:II-1) and in TPO/DUOX2 (9:II-3) genes. In the first case only the TPO variant would be the cause of the pathology due to the IYD variant is likely benign according to bioinformatics predictors.

In summary, five novel variants have been identified, two en TPO: c.2749-2A>C and c.2752_2753delAG, [p.Ser918Cysfs*62] and three variants in DUOX2 gene: c.425C>G [p.Pro142Arg]; c.790delC [p.Leu264Cysfs*57] and c.2695delC [p.GIn899Serfs*21] expanding so the causative mutation spectrum of TDH in Argentinian patients.

\section{Declarations}

\section{Availability of data and material}

Data and material are available from the authors upon request.

Acknowledgements M.F.M. and M.G.P. are research fellows of the Consejo Nacional de Investigaciones Científicas y Técnicas (CONICET). F.S.B., A.C., H.M.T., and C.M.R. are established investigators of the CONICET.

Author contributions M.F.M., F.S.B., E.B.M., E.A., M.C.O., M.G.P., H.M.T. and C.M.R. conducted experiments, specifically, M.F.M. contributed to performing Sanger sequencing, structural modeling analysis and checking references, F.S.B. contributed to performing Sanger sequencing, E.B.M. and C.M.R. 
contributed to performing and analyzing Next-Generation Sequencing, E.A. contributes with technical assistance of the experimental protocols, M.C.O. contributed to performing structural modeling protocols, M.G.P. and H.M.T. contributed to performing bioinformatic prediction tools. P.P., G.S., V.A.B., A.C., M.B.M. and V.G.G. were involved in the recruitment of patients and acquisition of clinical data and blood samples. R.G.-S. contributed to the acquisition of funds and the design of the study. H.M.T. and C.M.R. contributed to the acquisition of funds, the conception and design of the study and they contributed to the writing of the paper. C.M.R. is the study chief investigator. All authors critically reviewed and participated in manuscript revision and approved the final draft.

Funding This study was funded by grants from the Fondo para la Investigación Científica y Tecnológica (FONCyT-ANPCyT-MINCyT, PICT 2014-1193 to CMR, PICT 2015-1811 and PICT-2018-02146 to H.M.T.), Consejo Nacional de Investigaciones Científicas y Técnicas (CONICET, PIP 2015-11220150100499 to C.M.R.), Universidad de Buenos Aires (UBACyT 2016-20020150100099BA and 202020020190100050BA to C.M.R.) and Fondo de Investigación Sanitaria/FEDER (PI16/01920 and $\mathrm{PI} 20 / 01589$ to R.G.-S.).

\section{Compliance with ethical standards}

Ethical approvalThe studies involving human participants were reviewed and approved by the Ethical Committee of the Faculty of Pharmacy and Biochemistry of the University of Buenos Aires (CEIC-FFyB, No. 1094). Written informed consent was obtained from the parents of the children involved in this study.

Conflict of interest The authors declare no competing interests.

\section{References}

1. M.J. Kwak, Clinical genetics of defects in thyroid hormone synthesis. Ann. Pediatr. Endocrinol. Metab. 23, 169-175 (2018). http://doi.org/10.6065/apem.2018.23.4.169

2. A. Stoupa, D. Kariyawasam, M. Muzza, T. de Filippis, L. Fugazzola, M. Polak, L. Persani, A. Carré New genetics in congenital hypothyroidism. Endocrine 71, 696-705 (2021). http://doi.org/ 10.1007/s12020-021-02646-9

3. P. van Trotsenburg, A. Stoupa, J. Léger, T. Rohrer, C. Peters, L. Fugazzola, A. Cassio, C. Heinrichs, V. Beauloye, J. Pohlenz, P. Rodien, R. Coutant, G. Szinnai, P. Murray, B. Bartés, D. Luton, M. Salerno, L. de Sanctis, M. Vigone, H. Krude, L. Persani, M. Polak. Congenital hypothyroidism: a 2020-2021 consensus guidelines update-an ENDO-European reference network initiative endorsed by the 
European society for pediatric endocrinology and the European society for endocrinology. Thyroid 31, 387-419 (2021). http://doi.org/10.1089/thy.2020.0333

4. H.M. Targovnik, K.G. Scheps, C.M. Rivolta, Defects in protein folding in congenital hypothyroidism. Mol. Cell. Endocrinol. 501, 110638 ((2020). http://doi.org/10.1016/j.mce.2019.110638 ., )

5. F. Wang, Y. Zang, M. Li, W. Liu, Y. Wang, X. Yu, H. Li, F. Wang, S. Liu, DUOX2 and DUOXA2 variants confer susceptibility to thyroid dysgenesis and gland-in-situ with congenital hypothyroidism. Front. Endocrinol. (Lausanne) 11, 237 (2020). http://doi.org/10.3389/fendo.2020.00237

6. J.C. Moreno, H. Bikker, M.J.E. Kempers, A.S.P. van Trotsenburg, F. Baas, J.J.M. de Vijlder, T. Vulsma, C. Ris-Stalpers. Inactivating mutations in the gene for thyroid oxidase 2 (THOX2) and congenital hypothyroidism. N. Engl. J. Med. 347, 95-102 (2002). http://doi.org/10.1056/NEJMoa012752

7. C.M. Rivolta, S.A. Esperante, L. Gruñeiro-Papendieck, A. Chiesa, C.M. Moya, S. Domené, V. Varela, H.M. Targovnik, Five novel inactivating mutations in the human thyroid peroxidase gene responsible for congenital goiter and iodide organification defect. Hum. Mutat. 22, 259 (2003). http://doi.org/10.1002/humu.9175

8. S. Richards, N. Aziz, S. Bale, D. Bick, S. Das, J. Gastier-Foster, W.W. Grody, M. Hegde, E. Lyon, E. Spector, K. Voelkerding, H.L. Rehm, ACMG Laboratory Quality Assurance Committee, Standards and guidelines for the interpretation of sequence variants: a joint consensus recommendation of the American College of Medical Genetics and Genomics and the Association for Molecular Pathology. Genet. Med. 17, 405-424 (2015). http://doi.org/10.1038/gim.2015.30

9. S. Guria, B. Bankura, N. Balmiki, A.K. Pattanayak, T.K. Das, A. Sinha, S. Chakrabarti, S. Chowdhury, M. Das. Functional analysis of thyroid peroxidase gene mutations detected in patients with thyroid dyshormonogenesis. Int. J. Endocrinol. 2014, 390121 (2014). http://doi.org/10.1155/2014/390121

10. M.N. Begum, M.T. Islam, S.R. Hossain, G.S. Bhuyan, M.A. Halim, I. Shahriar, S.K. Sarker, S. Haque, T.K. Konika, M.S. Islam, A. Rahat, S.K. Qadri, R. Sultana, S. Begum, S. Sultana, N. Saha, M. Hasan, M.A. Hasanat, H. Banu, H.U. Shekhar, E.K. Chowdhury, A.A. Sajib, A.B.M.M.K. Islam, S.S. Qadri, F. Qadri, S. Akhteruzzaman, K. Mannoor. Mutation spectrum in TPO gene of Bangladeshi patients with thyroid dyshormonogenesis and analysis of the effects of different mutations on the structural features and functions of TPO protein through in silico approach. Biomed Res. Int. 2019, 9218903 (2019). http://doi.org/10.1155/2019/9218903

11. I. Oliver-Petit, T. Edouard, V. Jacques, M. Bournez, A. Cartault, S. Grunenwald, F. Savagner, Nextgeneration sequencing analysis reveals frequent familial origin and oligogenism in congenital hypothyroidism with dyshormonogenesis. Front. Endocrinol. (Lausanne) 12, 657913 (2021). http://doi.org/10.3389/fendo.2021.657913

12. F.S. Belforte, A.M. Targovnik, R.M. González-Lebrero, C. Osorio Larroche, C.E. Citterio, R. GonzálezSarmiento, M.V. Miranda, H.M. Targovnik, C.M. Rivolta, Kinetic characterization of human thyroperoxidase. Normal and pathological enzyme expression in Baculovirus system: a molecular model of functional expression. Mol. Cell. Endocrinol. 404, 9-15 (2015). http://doi.org/10.1016/j.mce.2014.12.026 
13. C. Fu, B. Xie, S. Zhang, J. Wang, S. Luo, H. Zheng, J. Su, X. Hu, R. Chen, X. Fan, J. Luo, X. Gu, S. Chen, Mutation screening of the TPO gene in a cohort of 192 Chinese patients with congenital hypothyroidism. BMJ Open 6, e010719 (2016). http://doi.org/10.1136/bmjopen-2015-010719

14. S.-G. Ma, X. Zheng, Y.-L. Qiu, M.-L. Guo, X.-J. Shao, Compound heterozygous mutations (p.T561M and c.2422delT) in the TPO gene associated with congenital hypothyroidism. J. Pediatr. Endocrinol. Metab. 29, 567-570 (2016). http://doi.org/10.1515/jpem-2015-0383

15. C.L.S. Santos, H. Bikker, K.G.M. Rego, A.C. Nascimento, M. Tambascia, J.J.M. de Vijlder, G. MedeirosNeto, A novel mutation in the TPO gene in goitrous hypothyroid patients with iodide organification defect. Clin. Endocrinol. (Oxf) 51, 165-172 (1999). http://doi.org/10.1046/j.1365-2265.1999.00746.x

16. A.C. Nascimento, D.R. Guedes, C.S. Santos, M. Knobel, I.G.S. Rubio, G. Medeiros-Neto.

Thyroperoxidase gene mutations in congenital goitrous hypothyroidism with total and partial iodide organification defect. Thyroid 13, 1145-1151 (2003). http://doi.org/10.1089/10507250360731550

17. C. Rodrigues, P. Jorge, J.P. Soares, I. Santos, R. Salomão, M. Madeira, R.V. Osório, R. Santos. Mutation screening of the thyroid peroxidase gene in a cohort of 55 Portuguese patients with congenital hypothyroidism. Eur. J. Endocrinol. 152, 193-198 (2005). http://doi.org/ 10.1530/eje.1.01826

18. J. Deladoëy, N. Pfarr, J.-M. Vuissoz, J. Parma, G. Vassart, S. Biesterfeld, J. Pohlenz, G. van, Vliet Pseudodominant inheritance of goitrous congenital hypothyroidism caused by TPO mutations: molecular and in silico studies. J. Clin. Endocrinol. Metab. 93, 627-633 (2008). http://doi.org/10.1210/jc.2007-2276

19. A.H.M. AL-Faisal, I.J. AL-Ramahi, I.A. Abudl-Hassan, A.T. Hamdan, S. Barusrux, Detection of heterozygous c. $1708 \mathrm{C}>\mathrm{T}$ and c. $1978 \mathrm{C}>\mathrm{G}$ thyroid peroxidase (TPO) mutations in Iraqi patients with toxic and nontoxic goiter. Comp. Clin. Pathol. 23, 69-75 (2014). http://doi.org/10.1007/s00580-0121572-9

20. R. Santos-Silva, M. Rosário, A. Grangeia, C. Costa, C. Castro-Correia, I. Alonso, M. Leão, M. Fontoura. Genetic analyses in a cohort of Portuguese pediatric patients with congenital hypothyroidism. J. Pediatr. Endocrinol. Metab. 32, 1265-1273 (2019). http://doi.org/10.1515/jpem-2019-0047

21. K. Umeki, T. Kotani, J. Kawano, T. Suganuma, I. Yamamoto, Y. Aratake, M. Furujo, Y. Ichiba, Two novel missense mutations in the thyroid peroxidase gene, R665W and G771R, result in a localization defect and cause congenital hypothyroidism. Eur. J. Endocrinol. 146, 491-498 (2002). http://doi.org/10.1530/eje.0.1460491

22. C.M. Figueiredo, I. Falcão, J. Vilaverde, J. Freitas, M.J. Oliveira, C. Godinho, J. Dores, M.C. Rodrigues, C. Carvalho, T. Borges. Prenatal diagnosis and management of a fetal goiter hypothyroidism due to dyshormonogenesis. Case Rep. Endocrinol. 2018, 9564737 (2018). http://doi.org/10.1155/2018/9564737

23. D. Zhao, Y. Li, Z. Shan, W. Teng, J. Li, X. Teng, Functional analysis of thyroid peroxidase gene mutations resulting in congenital hypothyroidism. Clin. Endocrinol. (Oxf) 93, 499-507 (2020). http://doi.org/10.1111/cen.14253 
24. T. de Filippis, G. Gelmini, E. Paraboschi, M.C. Vigone, M. di Frenna, F. Marelli, M. Bonomi, A. Cassio, D. Larizza, M. Moro, G. Radetti, M. Salerno, D. Ardissino, G. Weber, D. Gentilini, F. Guizzardi, S. Duga, L. Persani. A frequent oligogenic involvement in congenital hypothyroidism. Hum. Mol. Genet. 26, 25072514 (2017). http://doi.org/10.1093/hmg/ddx145

25. W. Long, G. Lu, W. Zhou, Y. Yang, B. Zhang, H. Zhou, L. Jiang, B. Yu. Targeted next-generation sequencing of thirteen causative genes in Chinese patients with congenital hypothyroidism. Endocr. J. 65, 1019-1028 (2018). http://doi.org/10.1507/endocrj.EJ18-0156

26. R.-J. Zhang, F. Sun, F. Chen, Y. Fang, C.-Y. Yan, C.-R. Zhang, Y.-X. Ying, Z. Wang, C.-X. Zhang, F.-Y. Wu, B. Han, J. Liang, S.-X. Zhao, H.-D. Song. The TPO mutation screening and genotype-phenotype analysis in 230 Chinese patients with congenital hypothyroidism. Mol. Cell. Endocrinol. 506, 110761 (2020). http://doi.org/10.1016/j.mce.2020.110761

27. H. Bikker, F. Baas, J.J.M. de Vijlder, Molecular analysis of mutated thyroid peroxidase detected in patients with total iodide organification defects. J. Clin. Endocrinol. Metab. 82, 649-653 (1997). http://doi.org/10.1210/jcem.82.2.3729

28. S. Pannain, R.E. Weiss, C.E. Jackson, D. Dian, J.C. Beck, V.C. Sheffield, N. Cox, and S. Refetoff Two different mutations in the thyroid peroxidase gene of a large inbred Amish kindred: power and limits of homozygosity mapping. J. Clin. Endocrinol. Metab. 84, 1061-1071 (1999). http://doi.org/10.1210/jcem.84.3.5541

29. B. Bakker, H. Bikker, T. Vulsma, J.S.E. de Randamie, B.M. Wiedijk, J.J.M. de Vijlder, Two decades of screening for congenital hypothyroidism in the Netherlands: TPO gene mutations in total iodide organification defect (an update). J. Clin. Endocrinol. Metab. 85, 3708-3712 (2000). http://doi.org/10.1210/jcem.85.10.6878

30. M. Avbelj, H. Tahirovic, M. Debeljak, M. Kusekova, A. Toromanovic, C. Krzisnik, T. Battelino, High prevalence of thyroid peroxidase gene mutations in patients with thyroid dyshormonogenesis. Eur. J. Endocrinol. 156, 511-519 (2007). http://doi.org/10.1530/EJE-07-0037

31. M.J. Abramowicz, H.M. Targovnik, V. Varela, P. Cochaux, L. Krawiec, M.A. Pisarev, F.V.E. Propato, G. Juvenal, H.A. Chester, G. Vassart, Identification of a mutation in the coding sequence of the human thyroid peroxidase gene causing congenital goiter. J. Clin. Invest. 90, 1200-1204 (1992). http://doi.org/10.1172/JCI115981

32. A. Grüters, B. Köhler, A. Wolf, A. Söling, L. de Vijlder, H. Krude, H. Biebermann, Screening for mutations of the human thyroid peroxidase gene in patients with congenital hypothyroidism. Exp. Clin. Endocrinol. Diabetes 104, 121-123 (1996). http://doi.org/10.1055/s-0029-1211718

33. F. Calaciura, G. Miscio, A. Coco, D. Leonardi, C. Cisternino, C. Regalbuto, M. Bozzali, R. Maiorana, A. Ranieri, A. Carta, M. Buscema, V. Trischitta, L. Sava, V. Tassi. Genetics of specific phenotypes of congenital hypothyroidism: a population-based approach. Thyroid 12, 945-951 (2002). http://doi.org/10.1089/105072502320908277

34. L. Fugazzola, D. Mannavola, M.C. Vigone, V. Cirello, G. Weber, P. Beck-Peccoz, L. Persani, Total iodide organification defect: clinical and molecular characterization of an Italian family. Thyroid 15, 10851088 (2005). http://doi.org/10.1089/thy.2005.15.1085 
35. F.S. Belforte, M.B. Miras, M.C. Olcese, G. Sobrero, G. Testa, L. Muñoz, L. Gruñeiro-Papendieck, A. Chiesa, R. González-Sarmiento, H.M. Targovnik, C.M. Rivolta, Congenital goitrous hypothyroidism: mutation analysis in the thyroid peroxidase gene. Clin. Endocrinol. (Oxf) 76, 568-576 (2012). http://doi.org/10.1111/j.1365-2265.2011.04249.x

36. K. Altmann, P. Hermanns, R. Mühlenberg, S. Fricke-Otto, R. Wentzell, J. Pohlenz, Congenital goitrous primary hypothyroidism in two German families caused by novel thyroid peroxidase (TPO) gene mutations. Exp. Clin. Endocrinol. Diabetes 121, 343-346 (2013). http://doi.org/ 10.1055/s-00331333766

37. H. Cangul, Z. Aycan, A. Olivera-Nappa, H. Saglam, N.A. Schoenmakers, K. Boelaert, S. Cetinkaya, O. Tarim, E. Bober, F. Darendeliler, V. Bas, K. Demir, B.K. Aydin, M. Kendall, T. Cole, W. Högler, V.K.K. Chatterjee, T.G. Barrett, E.R. Maher, Thyroid dyshormonogenesis is mainly caused by TPO mutations in consanguineous community. Clin. Endocrinol. (Oxf) 79, 275-281 (2013).

http://doi.org/10.1111/cen.12127

38. H. Cangul, B.K. Aydin, F. Bas, A homozygous TPO gene duplication (c.1184_1187dup4) causes congenital hypothyroidism in three siblings born to a consanguineous family. J. Pediatr. Genet. 4, 194-198 (2015). http://doi.org/10.1055/s-0035-1565268

39. C. Löf, K. Patyra, T. Kuulasmaa, J. Vangipurapu, H. Undeutsch, H. Jaeschke, T. Pajunen, A. Kero, H. Krude, H. Biebermann, G. Kleinau, P. Kühnen, K. Rantakari, P. Miettinen, T. Kirjavainen, J.-P. Pursiheimo, T. Mustila, J. Jääskeläinen, M. Ojaniemi, J. Toppari, J. Ignatius, M. Laakso, J. Kero. Detection of novel gene variants associated with congenital hypothyroidism in a Finnish patient cohort. Thyroid 26, 1215-1224 (2016). http://doi.org/10.1089/thy.2016.0016

40. A.K. Nicholas, E.G. Serra, H. Cangul, S. Alyaarubi, I. Ullah, E. Schoenmakers, A. Deeb, A.M. Habeb, M. Almaghamsi, C. Peters, N. Nathwani, Z. Aycan, H. Saglam, E. Bober, M. Dattani, S. Shenoy, P.G. Murray, A. Babiker, R. Willemsen, A. Thankamony, G. Lyons, R. Irwin, R. Padidela, K. Tharian, J.H. Davies, V. Puthi, S.-M. Park, A.F. Massoud, J.W. Gregory, A. Albanese, E. Pease-Gevers, H. Martin, K. Brugger, E.R. Maher, V.K.K. Chatterjee, C.A. Anderson, N. Schoenmakers. Comprehensive screening of eight causatives genes in congenital hypothyroidism with gland-in-situ. J. Clin. Endocrinol. Metab. 101, 4521-4531 (2016). http://doi.org/10.1210/jc.2016-1879

41. N. Makretskaya, O. Bezlepkina, A. Kolodkina, A. Kiyaev, E.V. Vasilyev, V. Petrov, S. Kalinenkova, O. Malievsky, I.I. Dedov, A. Tiulpakov, High frequency of mutations in 'dyshormonogenesis genes' in severe congenital hypothyroidism. Plos One 13, e0204323 (2018).

http://doi.org/10.1371/journal.pone.0204323

42. M. Zou, A.S. Alzahrani, A. Al-Odaib, M.A. Alqahtani, O. Babiker, R.A. Al-Rijjal, H.A. BinEssa, W.E. Kattan, A.F. Al-Enezi, A. Al Qarni, M.S.A. Al-Faham, E.Y. Baitei, A. Alsagheir, B.F. Meyer, Y. Shi, Molecular analysis of congenital hypothyroidism in Saudi Arabia: SLC26A7 mutation is a novel defect in thyroid dyshormonogenesis. J. Clin. Endocrinol. Metab. 103, 1889-1898 (2018).

http://doi.org/10.1210/jc.2017-02202

43. N. Zdraveska, M. Kocova, A.K. Nicholas, V. Anastasovska, N. Schoenmakers, Genetics of gland-in-situ or hypoplastic congenital hypothyroidism in Macedonia. Front. Endocrinol. (Lausanne) 11, 413 
(2020). http://doi.org/10.3389/fendo.2020.00413

44. T. Kotani, K. Umeki, I. Yamamoto, H. Maesaka, K. Tachibana, S. Ohtaki, A novel mutation in the human thyroid peroxidase gene resulting in a total iodide organification defect. J. Endocrinol. 160, 267-273 (1999). http://doi.org/10.1677/joe.0.1600267

45. S.-T. Lee, D.H. Lee, J.-Y. Kim, M.-J. Kwon, J.-W. Kim, Y.-H. Hong, Y.-W. Lee, C.-S. Ki. Molecular screening of the TSH receptor (TSHR) and thyroid peroxidase (TPO) genes in Korean patients with nonsyndromic congenital hypothyroidism. Clin. Endocrinol. (Oxf) 75, 715-721 (2011). http://doi.org/10.1111/j.1365-2265.2011.04156.x

46. M. Muzza, S. Rabbiosi, M.C. Vigone, I. Zamproni, V. Cirello, M.A. Maffini, K. Maruca, N. Schoenmakers, L. Beccaria, F. Gallo, S.-M. Park, P. Beck-Peccoz, L. Persani, G. Weber, L. Fugazzola, The clinical and molecular characterization of patients with dyshormonogenic congenital hypothyroidism reveals specific diagnostic clues for DUOX2 defects. J. Clin. Endocrinol. Metab. 99, E544-E553 (2014). http://doi.org/10.1210/jc.2013-3618

47. Y. Maruo, K. Nagasaki, K. Matsui, Y. Mimura, A. Mori, M. Fukami, Y. Takeuchi, Natural course of congenital hypothyroidism by dual oxidase 2 mutations from the neonatal period through puberty. Eur. J. Endocrinol. 174, 453-463 (2016). http://doi.org/10.1530/EJE-15-0959

48. V. Varela, C.M. Rivolta, S.A. Esperante, L. Gruñeiro-Papendieck, A. Chiesa, H.M. Targovnik, Three mutations (p.Q36H, p.G418fsX482, and g.IVS19-2A_C) in the dual oxidase 2 gene responsible for congenital goiter and iodide organification defect. Clin. Chem. 52, 182-191 (2006). http://doi.org/10.1373/clinchem.2005.058321

49. G. De Marco, P. Agretti, L. Montanelli, C. Di Cosmo, B. Bagattini, M. De Servi, E. Ferrarini, A. Dimida, A.C. Freitas Ferreira, A. Molinaro, C. Ceccarelli, F. Brozzi, A. Pinchera, P. Vitti, M. Tonacchera, Identification and functional analysis of novel dual oxidase 2 (DUOX2) mutations in children with congenital or subclinical hypothyroidism. J. Clin. Endocrinol. Metab. 96, E1335-E1339 (2011). http://doi.org/10.1210/jc.2010-2467

50. P. Srichomkwun, J. Takamatsu, D.A. Nickerson, M.J. Bamshad, J.X. Chong, S. Refetoff. DUOX2 gene mutation manifesting as resistance to thyrotropin phenotype. Thyroid 27, 129-131 (2017). http://doi.org/10.1089/thy.2016.0469

51. K. Sorapipatcharoen, T. Tim-Aroon, P. Mahachoklertwattana, W. Chantratita, N. lemwimangsa, I. Sensorn, B. Panthan, P. Jiaranai, S. Noojarern, P. Khlairit, S. Pongratanakul, C. Suprasongsin, M. Korwutthikulrangsri, C. Sriphrapradang, P. Poomthavorn. DUOX2 variants are a frequent cause of congenital primary hypothyroidism in Thai patients. Endocr. Connect. 9, 1121-1134 (2020). http://doi.org/10.1530/EC-20-0411

52. M.V. Rastogi, S.H. LaFranchi, Congenital hypothyroidism Orphanet J. Rare Dis. 5, 17 (2010). http://doi.org/10.1186/1750-1172-5-17

53. A. Stoupa, R. Chaabane, M. Guériouz, C. Raynaud-Ravni, P. Nitschke, C. Bole-Feysot, M. Mnif, L. Ammar Keskes, M. Hachicha, N. Belguith, M. Polak, A. Carré, Thyroid hypoplasia in congenital hypothyroidism associated with thyroid peroxidase mutations. Thyroid 28, 941-944 (2018). http://doi.org/10.1089/thy.2017.0502 
54. F. Wang, K. Lu, Z. Yang, S. Zhang, W. Lu, L. Zhang, S. Liu, S. Yan, Genotypes and phenotypes of congenital goitre and hypothyroidism caused by mutations in dual oxidase 2 genes. Clin. Endocrinol. (Oxf) 81, 452-457 (2014). http://doi.org/10.1111/cen.12469

55. C. Peters, A.K. Nicholas, E. Schoenmakers, G. Lyons, S. Langham, E.G. Serra, N.J. Sebire, M. Muzza, L. Fugazzola, N. Schoenmakers, DUOX2/DUOXA2 mutations frequently cause congenital hypothyroidism that evades detection on newborn screening in the United Kingdom. Thyroid 29, 790801 (2019). http://doi.org/10.1089/thy.2018.0587

56. M. Tan, Y. Huang, X. Jiang, P. Li, C. Tang, X. Jia, Q. Chen, W. Chen, H. Sheng, Y. Feng, D. Wu, L. Liu, The prevalence, clinical, and molecular characteristics of congenital hypothyroidism caused by DUOX2 mutations: a population-based cohort study in Guangzhou. Horm. Metab. Res. 48, 581-588 (2016). http://doi.org/10.1055/s-0042-112224

57. X. Fan, C. Fu, Y. Shen, C. Li, S. Luo, Q. Li, J. Luo, J. Su, S. Zhang, X. Hu, R. Chen, X. Gu, S. Chen, Nextgeneration sequencing analysis of twelve known causative genes in congenital hypothyroidism. Clin. Chim. Acta. 468, 76-80 (2017). http://doi.org/10.1016/j.cca.2017.02.009

58. S. Liu, W. Han, Y. Zang, H. Zang, F. Wang, P. Jiang, H. Wei, X. Liu, Y. Wang, X. Ma, Y. Ge, Identification of two missense mutations in DUOX1 (p.R1307Q) and DUOXA1 (p.R56W) that can cause congenital hypothyroidism through impairing $\mathrm{H}_{2} \mathrm{O}_{2}$ generation. Front. Endocrinol. (Lausanne) 10, 526 (2019). http://doi.org/10.3389/fendo.2019.00526

59. H. Cangul, X.-H. Liao, E. Schoenmakers, J. Kero, S. Barone, P. Srichomkwun, H. Iwayama, E.G. Serra, H. Saglam, E. Eren, O. Tarim, A.K. Nicholas, I. Zvetkova, C.A. Anderson, F.E.K. Frankl, K. Boelaert, M. Ojaniemi, J. Jääskeläinen, K. Patyra, C. Löf, E.D. Williams, U.K.K. Consortium, M. Soleimani, T. Barrett, E.R. Maher, V.K. Chatterjee, S. Refetoff, N. Schoenmakers. Homozygous loss-of-function mutations in SLC26A7 cause goitrous congenital hypothyroidism. JCl insight 3, e99631 (2018). http://doi.org/10.1172/jci.insight.99631

60. X. De Deken, F. Miot. DUOX defects and their roles in congenital hypothyroidism. In: Knaus U.G., L. Leto T.L. (eds.) NADPH Oxidases: Methods and Protocols, Methods in Molecular Biology, vol. 1982, pp. 667-693. Springer Science+Business Media, LLC (2019)

\section{Tables}

Tables 1 - 3 can be accessed/downloaded from the Supplementary Files section.

\section{Figures}




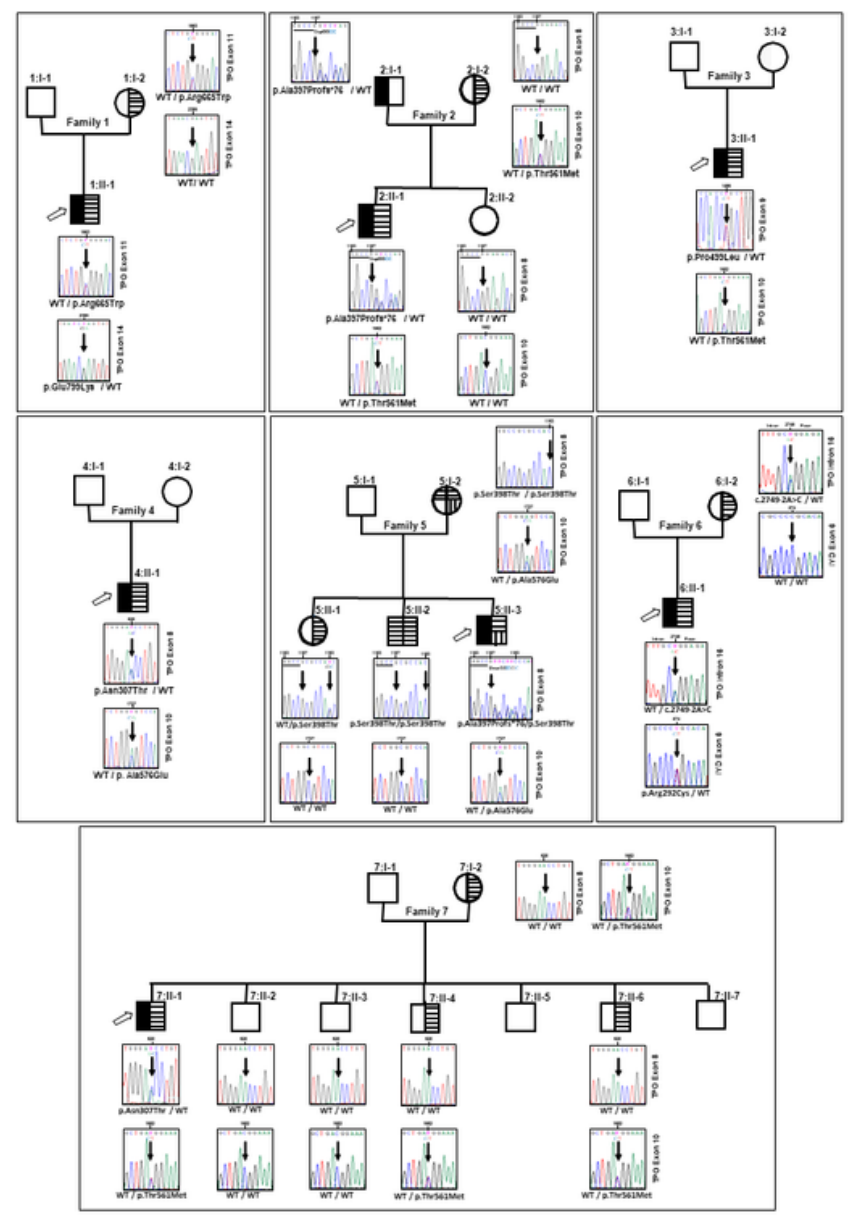

$A$

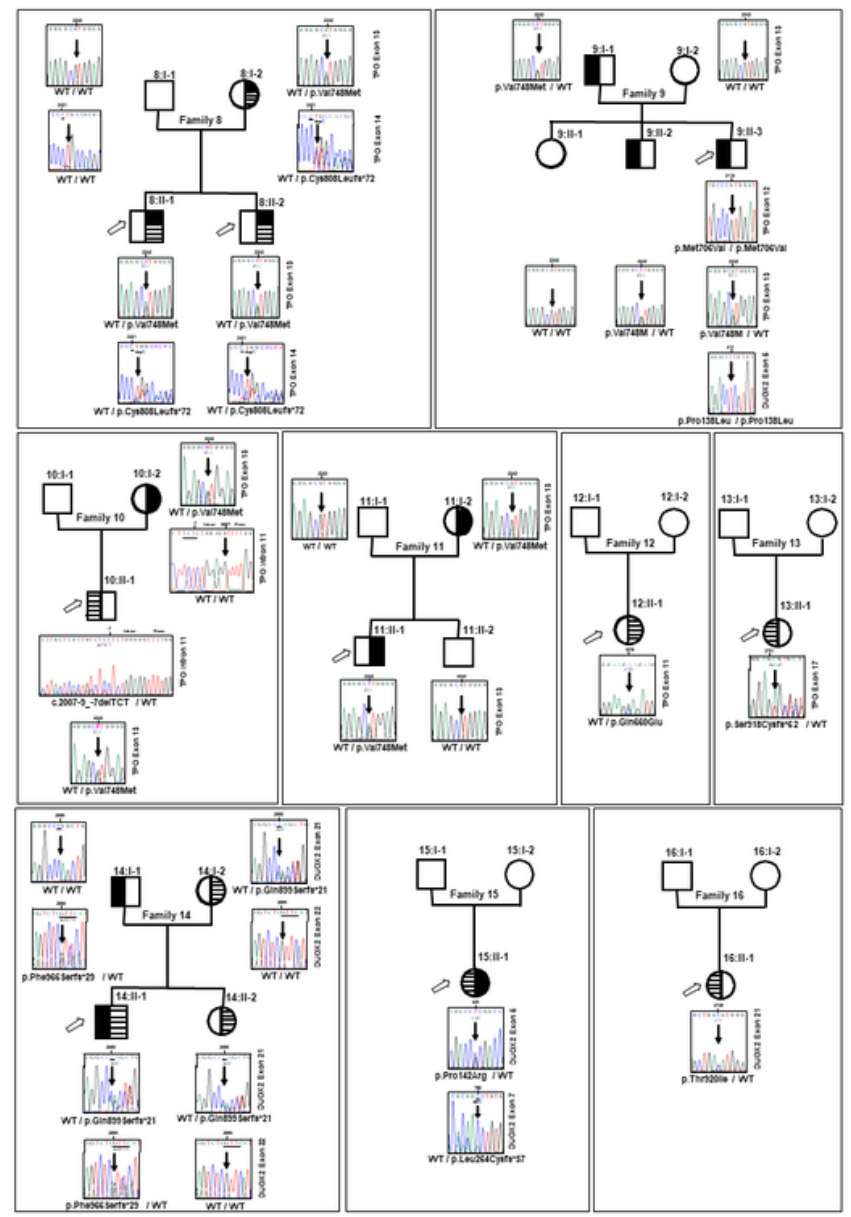

$B$

\section{Figure 1}

\section{a, b. Pedigrees showing the thyroid peroxidase (TPO), dual oxidase 2 (DUOX2) and iodotyrosine}

deiodinase (IYD) genotype results for the families from 1 to 16 . Partial sequencing chromatograms of genomic DNA are shown. Squares represent males and circles females. Filled symbols denote affected individuals and half-filled symbols, unaffected heterozygous individuals. The solid symbols indicate the p.Glu799Lys, p.Ala397Profs*76, p.Pro499Leu, p.Asn307Thr, p.Arg292Cys, p.Val748Met, p.Phe966Serfs $\star 29$, p.Leu264Cysfs ${ }^{*} 57$ mutated alleles and the hatched symbols the p.Arg665Trp, p.Thr561Met, p.Ala576Glu, p.Ser398Thr, p.Ala576Glu, c.2749-2A>C, p.Cys808Leufs*72, c.2007-9_-7delTCT, p.GIn660Glu, p.Ser918Cysfs*62, p.GIn899Serfs*21, p.Pro142Arg and p.Thr920lle mutated alleles. Sense strands are shown except for sequences c.2007-9_-7delTCT/WT (Family 10:II-1) and p.Leu264Cysfs*57/WT (Family 15:II-1). Black arrows denote the position of identified mutations, single chromatogram peaks indicate homozygosity and two overlapping peaks at the same locus, heterozygosity. The DNA of the fathers from families 1 (1:I-1), 5 (5:I-1), 6 (6:I-1), 7 (7:I-1), 10 (10:I-1) and the fathers and mothers from families 3 (3:I-1, 3:I-2), 4 (4:I-1, 4:I-2), 12 (12:I-1, 12:I-2), 13 (13:I-1, 13:I-2), 15 (15:I-1, 15:I-2) and 16 (16:I-1, 16:I-2) were not available for analysis. Families 8 (8:II-1, 8:II-2), 11 (11:II-1), 12 (12:II-1), 13 (13:II-1) and 16 (16:II-1) did not show a second inactivating mutation. Open arrows denote 
index patient. The nucleotide position is designated according to the Homo sapiens TPO, DUOX2 and IYD mRNA sequence reported in the National Center for Biotechnology Information (NCBI), reference sequence: NM_000547.6, NM_014080.5 and NM_001164694.2, respectively. The A of the ATG of the initiator methionine codon is denoted nucleotide +1 . The amino acid positions are numbered including the signal peptide, following the NCBI (TPO: NP_000538, DUOX2: NP_054799, IYD: NP_001158166.1) and Uniprot (TPO: P07202, DUOX2: Q6PHW0, IYD: Q9NRD8) numbering.

The wild-type and mutated amplified fragments corresponding to exons: 8 (Family 2:II-1 and Family 5:II-3), 12 (Family 10:II-1), 14 (Family 8:II-2) and 17 (Family 13:II-1) of the TPO gene and exons: 7 (Family 15:II-1), 21 (Family 14:II-1) and 22 (Family 14:II-1) of the DUOX2 gene were T-A cloned into pGEM-T Easy vector (Promega, Madison, WI, USA) and sequenced using the T7 primer.

a

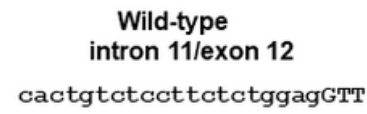

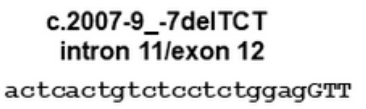

intron $\overline{11}$ exon 12
actcactgtctcctctggagGTT

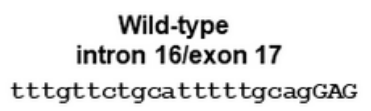

0

5.40

0.74

24

0.39

1.48

3.29

tttgttctgcatttttgcagGAG

0.95

11.35

0.66

80

9.13

10.62

11.26

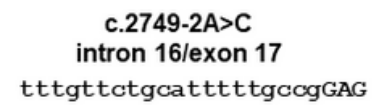

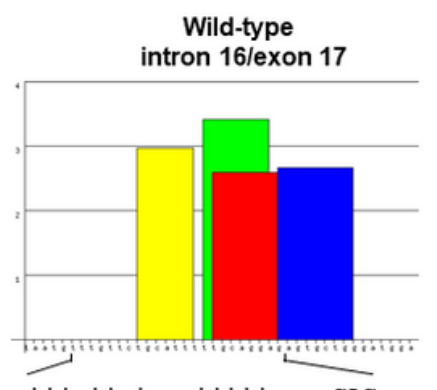

tttgttctgcatttttgcagGAG
0

0

0

0

1.08

2.58

3.21 b

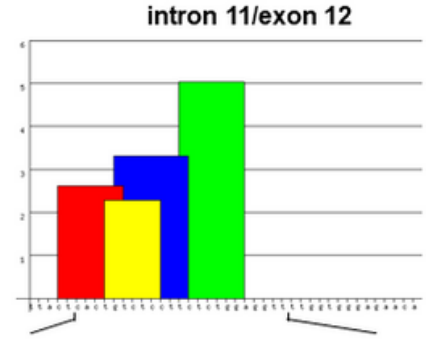

cactgtctccttctctggagGTT

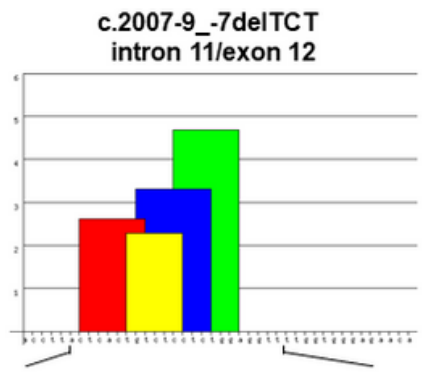

actcactgtctcctctggagGTT

SF2IASF

SC 35

SRp40

SRp55

\section{Figure 2}

\section{c.2007-9_-7delTCT and c.2749-2A>C thyroid peroxidase (TPO) variants, in silico analysis of the wild-type} and mutated 3' splice sites. a) Individual scores for each 3' splice sites obtained by a panel of acceptor site prediction programs (NNSplice, FSplice, SPL, SPLM and MaxEntScan program by selecting for the analyses the maximum entropy model (MAXENT), the first-order Markov model (MM) and the weight matrix model (WMM)). The NNSplice, FSplice, SPL, SPLM splice site models assign a log-odd ratio (score) to a 23-mer (3'ss) sequence. The higher the score, the higher the probability that the sequence is a true splice site. b) Potential SR binding sites (SF2/ASF, SC35, SRp40 and SRp55) identified by the ESEfinder 
3.0 program. The height of each bar represents the motif scores, whereas its width indicates the length of the binding site motifs for SR proteins and its position along the sequence. Note that the wild-type and mutated 3' splice site are potentially recognizable by SR proteins.

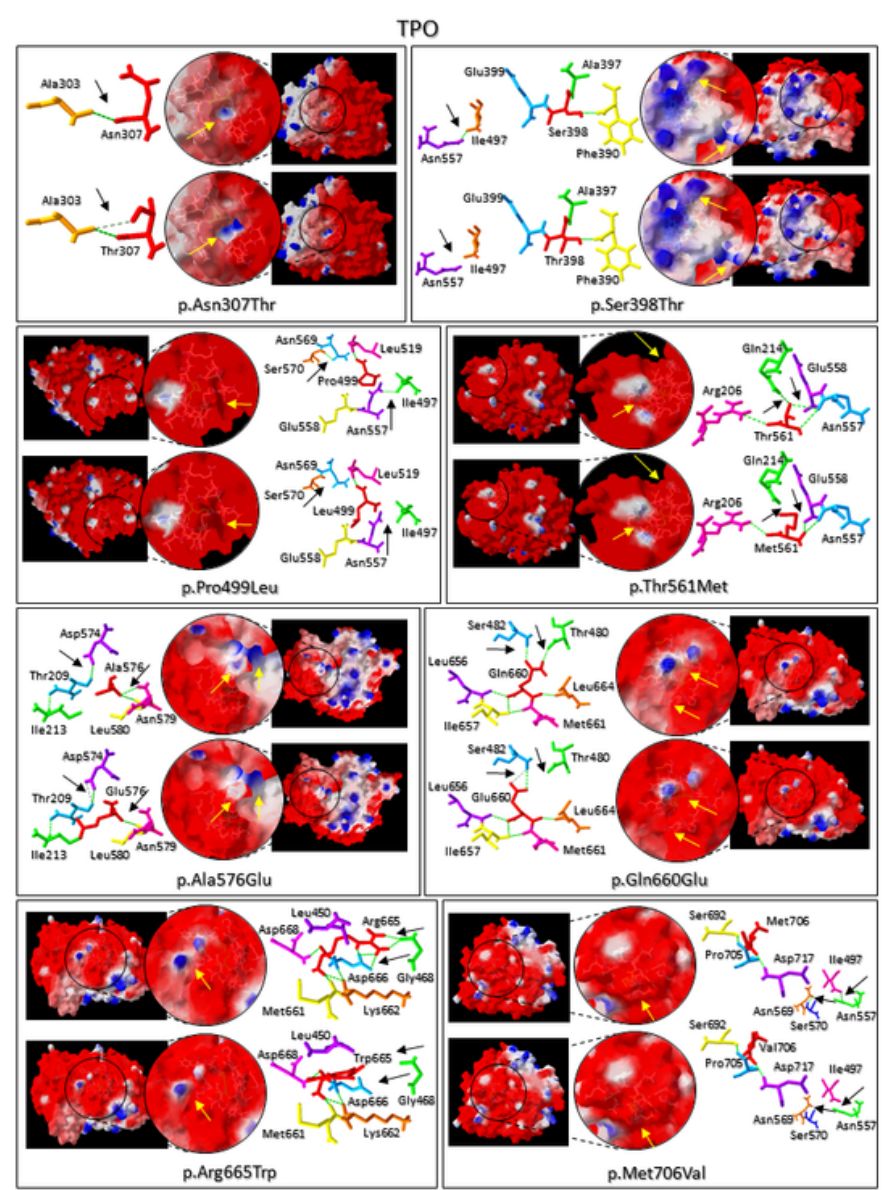

$A$
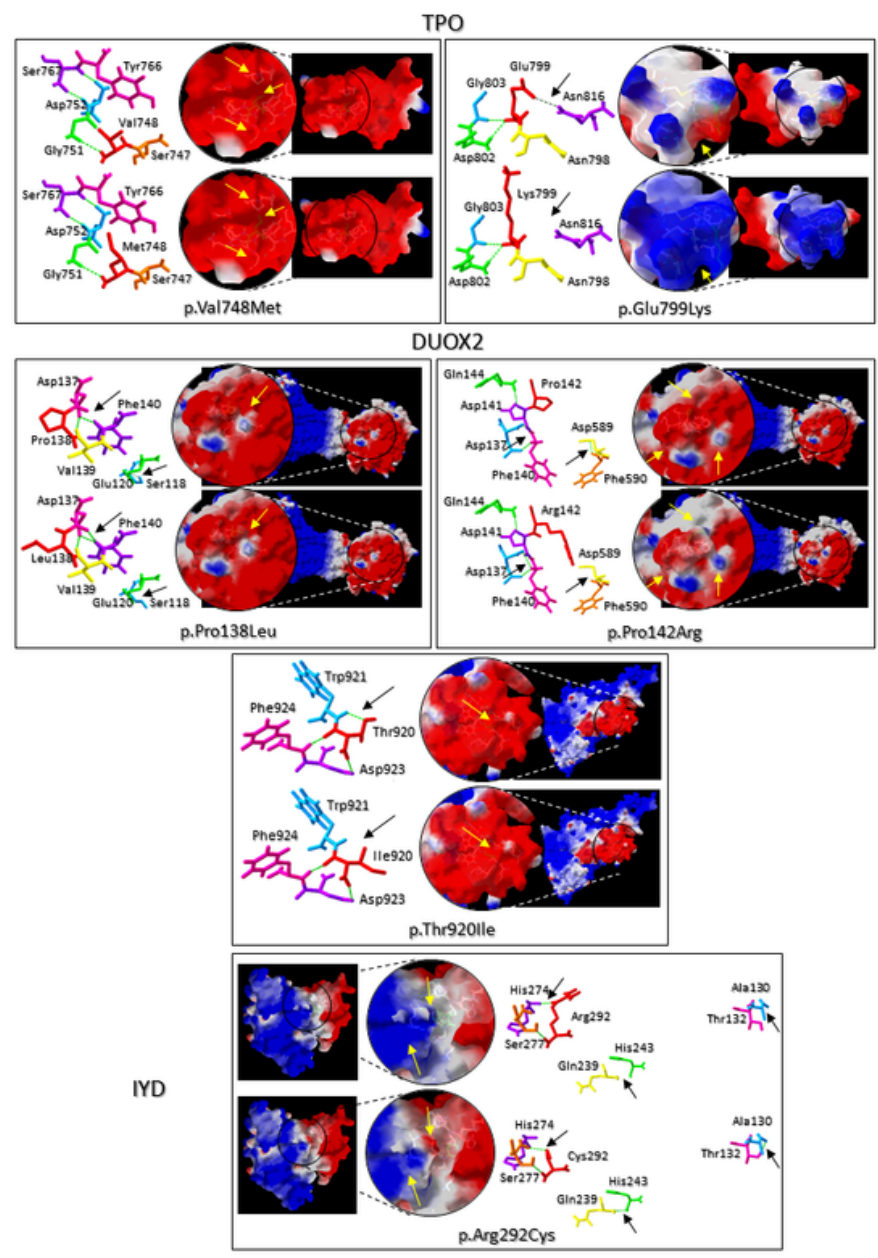

$B$

Figure 3

a, b. Tertiary structure prediction of the identified human thyroid peroxidase (TPO), dual oxidase 2 (DUOX2) and iodotyrosine deiodinase (IYD) mutants. The different protein models were submitted to the Swiss PDB Viewer v4.1.0 in order to evaluate potential structure changes due to mutations. Electropositive charges are shown in blue, electronegative charges in red and neutral areas appears in white. Stability changes were calculated using the FoldX suite through the artificial reality application YASARA. The arrows indicate the differences in the protein structure. 

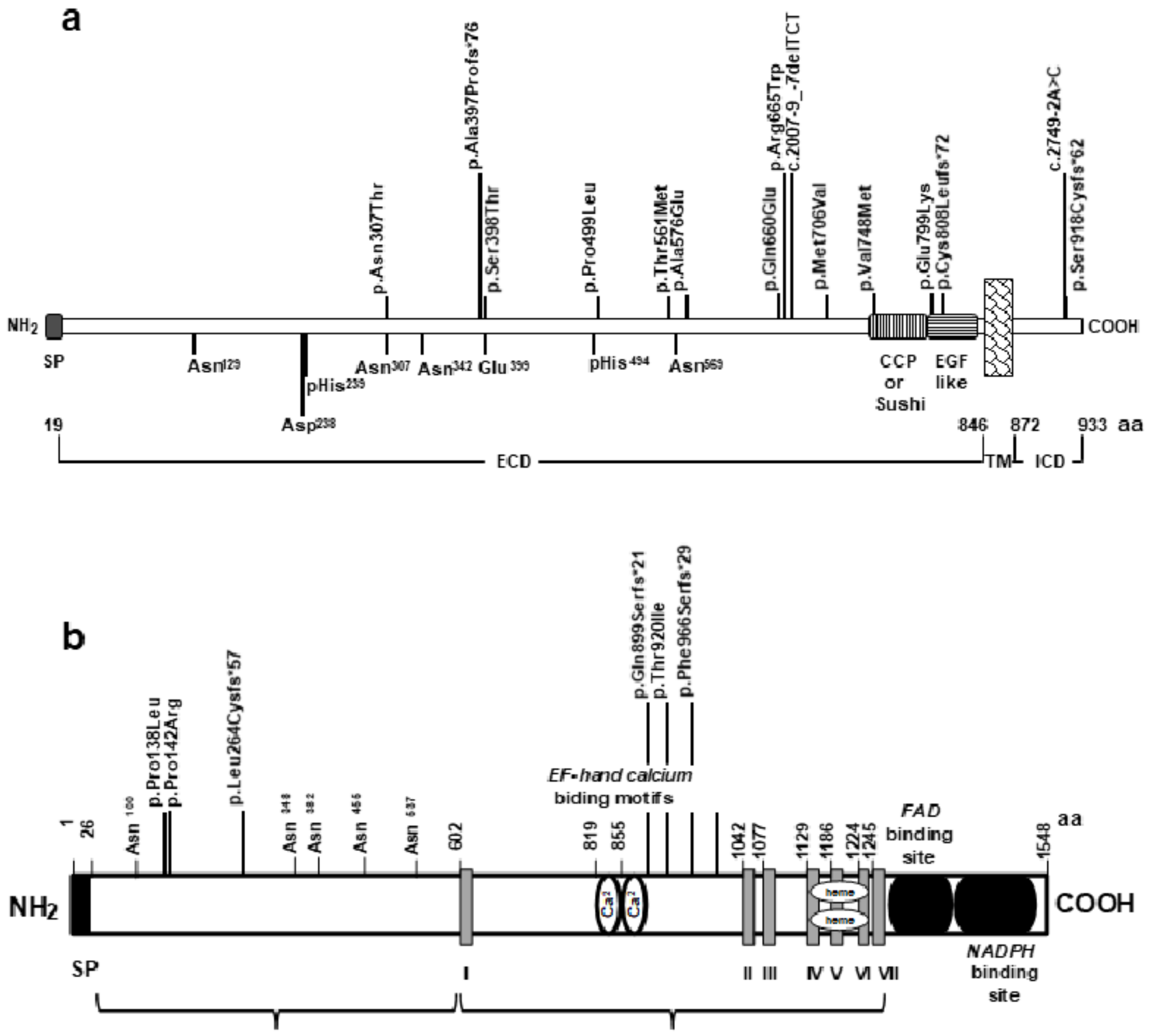

Peroxidase-like domain

Apha helice trans membrane domain

gp91 9 phex/NOX2-like d omain

Figure 4

Structural organization of the thyroid peroxidase (TPO) and dual oxidase (DUOX2) proteins with reference to the position of the identified variants. a) TPO variants. The signal peptide (SP), complement control protein (CCP) domain, also known as Sushi domain, calcium-binding EGF (EGF like) domain and hemebinding sites (proximal histidine $\left(\mathrm{pHis}^{494}\right)$, distal histidine $\left(\mathrm{dHis}^{239}\right)$, aspartic acid $\left(\mathrm{Asp}^{38}\right)$, glutamic acid $\left(\mathrm{Glu}^{399}\right)$, drawn to scale, are shown. The identified TPO variants are indicated. The amino acid positions 
are numbered including the signal peptide (SP), following the NCBI (NP_000538) and Uniprot (P07202) numbering. ECD: extracellular domain, TM: transmembrane domain, ICD: intracellular domain, aa: amino acid. b) DUOX2 variants. The peroxidase-like and gp91 phox/NOX2-like domains, glycosilation sites (NXS/T site), EF-hand calcium binding motifs and FAD and NADPH binding sites, drawn to scale, are shown. The seven alpha helice transmembrane domains are represented by boxes (I, II, III, IV, V, VI and VII). The identified TPO variants are indicated. The amino acid positions are numbered including the signal peptide, following the NCBI (NP_054799) and Uniprot (Q6PHW0) numbering.

\section{Supplementary Files}

This is a list of supplementary files associated with this preprint. Click to download.

- Table2inreview.pdf

- Table1inreview.pdf

- SupplementaryMaterial.pdf

- Table1 inreview.pdf

- Table3inreview.pdf

- Table3inreview.pdf 